\title{
SITAGLIPTIN; SITAGLIPTIN AS ADD ON THERAPY TO PATIENTS ON INSULIN.
}

\footnotetext{
1. MBBS, FCPS (Medicine) Senior Registrar, Medical Unit I, Sir Ganga Ram Hospital, Lahore. 2. MBBS

Medical Officer, BHU, Faisalabad.

3. MBBS, FCPS (Medicine) Medical Officer, Department of Endocrinology, Services Hospital, Lahore.
}

Correspondence Address: Dr. Zaheer Ahmad House No. 35-C PMC Colony,

Faisalabad.

trueman228@gmail.com

Article received on: 21/07/2017

Accepted for publication 23/09/2017

Received after proof reading: 03/11/2017

\section{Zaheer Ahmed ${ }^{1}$, Hassan Fareed ${ }^{2}$, Muhammad Usman Musharraf ${ }^{3}$}

ABSTRACT... The objective of this stidy is to compare the mean reduction of $\mathrm{HbA1c}$ in patients taking sitagliptin insulin combination with insulin alone in patients of type II Diabetes mellitus. Study Design: Randomized control trial (RCT). Setting: Medicine Department, Allied Hospital, Faisalabad. Period: August 2013 to February 2014. Methodology: Patients of both genders with ages between 18 and 60 years having uncontrolled type 2 diabetes mellitus with $\mathrm{HbA1c}$ taking insulin were included in the study while Pregnant or lactating mothers, patients with chronic liver disease and patients with renal insufficiency (creatinine $>3.0 \mathrm{mg} / \mathrm{dl}$ ) were excluded from study. Patients were randomly divided into two groups (A \&B) using computer generated random number table. Group A was given Sitagliptin $50 \mathrm{mg}$ per day and dose was increased to $100 \mathrm{mg}$ per day after 2 weeks if fasting blood sugar was more than $110 \mathrm{mg} / \mathrm{dl}$ or 2 hours postprandial blood sugar more than $140 \mathrm{mg} / \mathrm{dl}$. Dose of insulin in group A remained same as before start of study. Group B was kept on same regimen of insulin they were already taking and dose remained same. $\mathrm{HbA1c}$ was done at start of study and after 24 weeks. Primary outcome measure was mean reduction in $\mathrm{HbA1c}$ levels at 24 weeks from baseline. Results: 60 patients were included in the study. Mean age was $52.7 \pm 8.43$ years. $36(60 \%)$ were male and $24(40 \%)$ were female. Mean $\mathrm{HbA} 1 \mathrm{c}$ at baseline was $8.361 \pm 0.523 \%$ in Group A on Sitagliptin-insulin combination and $8.187 \pm 0.432 \%$ in group $B$ on insulin alone. Mean $\mathrm{HbA1C}$ at 24 weeks was $7.767 \pm 0.428 \%$ in group $A$ on Sitagliptin-insulin combination and $7.69 \pm 0.407 \%$ in group $B$ on insulin alone.Independent sample t-test was applied to change in $\mathrm{HbA} 1 \mathrm{c}$ in Group $A$ and $B$ during 24 weeks of treatment. Mean change in $\mathrm{HbA} 1 \mathrm{c}$ after 24 weeks in Group A was 0.600 \pm 0.315 and $0.49 \pm 0.19$ in Group B after 24 weeks treatment ( $p$-value 0.002) which is highly significant. Paired sample t-test was applied to $\mathrm{HbA} 1 \mathrm{c}$ at baseline and 24 weeks of treatment in group $A$ and group $B$. There was a significant change in both groups after 24 weeks of treatment in both groups ( $p$-value $<0.000$ ) which is highly significant. Chi Square test was applied on efficacy in group A and B. 22(73.33\%) patients in group A and 14(46.67\%) patients in group $B$ which achieved significant reduction in HbA1c. 8(26.67\%) patients in group A and 16(53.33\%) patients in group $B$ failed to achieve significant reduction in HbA1c. (P-value < 0.032). Conclusion: It has been concluded from this study that insulin and sitagliptin-insulin combination both significantly reduce $\mathrm{HbA1c}$ in type 2 diabetes mellitus. However addition of sitagliptin to uncontrolled diabetic patients already taking insulin, is more effective than insulin for glycemic control of patients with type 2 diabetes mellitus.

Key words: $\quad$ Type 2 Diabetes Mellitus, Insulin, Sitagliptin.

Article Citation: Ahmed Z, Fareed H, Musharraf MU. Sitagliptin; as add on therapy to patients on insulin. Professional Med J 2017;24(11):1755-1760.

DOI:10.17957/TPMJ/17.4444

\section{INTRODUCTION}

Diabetes Mellitus (DM) is the most common chronic conditions prevalent worldwide TypeIIDM constitutes $90 \%$ of all DM cases. ${ }^{1}$ Glycemic control maintenance is the primary treatment goal for type-II DM. Japanese Kumamoto study ${ }^{2}$ and UKPDS study ${ }^{3}$ which are the land trials in DM, have established the fact that excellent glycemic control with insulin therapy decreases risk of microvascular complications, in people with typeII DM. DM is a rising epidemic, especially type-II DM in Pakistan and is putting an unbearable burden on economy and adversely affecting quality of life of people with DM due to poor glycemic control and resultant high rates of complications. Resource utilization is unacceptably high. Society, 
Resource constraints, lack of medical insurance system and insufficiently allocated health funds are major reasons for deficient quality care. Most of the people with Type-II DM are not able to afford the high cost of treatment. ${ }^{4}$

DM is an ever increasing epidemic that is adding to so many chronic diseases like Cardiovascular, Cerebrovascular, End Stage Kidney Disease and Retinopathies. If treated earlier, the dreaded consequences of these complications can be avoided. These complications have a broad spectrum and attributable largely to chronically elevated glycemic levels resulting in damage to intima of the blood vessels. In diabetes, the resulting complications are grouped under "microvascular disease" (due to damage to small blood vessels) and "macrovascular disease" (due to damage to the arteries)..$^{5}$ Glycemic control tends to deteriorate over time because of beta cell loss which occurs over time in type-II DM. ${ }^{6}$ Patients must be started on combination therapy at this stage of disease. ${ }^{7}$

DPP-IV Inhibitors were introduced in 2006 and these have shown promising results in glycemic control in type-IIDM. ${ }^{8}$ Six different DPP $\square$ IV inhibitors are available: sitagliptin, alogliptin, vildagliptin, teneligliptin, linagliptin and anagliptin. Sitagliptin is most commonly used among these and its safety profile and efficacy are proven in many trials. ${ }^{9}$ Sitagliptin might be more effective for glycemic control in some ethnic populations as well. ${ }^{10}$ In many trials, $\mathrm{HbA} 1 \mathrm{c}$ improvement ranged from $0.5 \%$ to $1.4 \% .{ }^{11}$ Sitagliptin can be used in combination with sulfonylureas, insulin and metformin. ${ }^{12,13,14}$ Sitagliptin combination has shown the advantage of better glycemic control, less hypoglycemic events and a decrease in number of units of insulin in patients who were already taking insulin. ${ }^{15}$ There is no increase in hypoglycemia incidence when used alone or in combination with euglycemic drugs such as metformin and thiazolidinediones but there can be hypoglycemia in combination with sulfonylureas or insulin. ${ }^{16}$ It can also be used in patients with liver disease ${ }^{17}$ and kidney disease. ${ }^{18}$ Sitagliptin dosage can be adjusted based on renal function. These properties make this medication an attractive option for the treatment of diabetes in renal disease as well. ${ }^{19}$

Addition of sitagliptin to insulin is quite safe and it results in decreased episodes of hypoglycemia, ${ }^{20}$ better glycemic control and decreased requirement of insulin unit in patients with typeIIDM. ${ }^{21}$

Keeping in view the potential advantages of Sitagliptin like better Glycemic control and less hypoglycemic events, we will compare the Sitagliptin-insulin combination with insulin alone. This will provide us a better insight into efficacy in patients taking Sitagliptin and insulin and this will help us formulate recommendations for patients who require combination of Sitagliptin with insulin.

\section{OBJECTIVE}

I compared the mean reduction of $\mathrm{HbA} 1 \mathrm{c}$ in patients taking Sitagliptin-insulin combination with insulin alone in patients of Type 2 Diabetes Mellitus.

\section{MATERIALS \& METHODS}

It was a RCT done at Medicine Department, Allied Hospital, Faisalabad from August 2013 to February 2014. Approval from hospital ethical review committee was taken after formulation of synopsis. Patients fulfilling the inclusion criteria were enrolled in the study. Total 60 patients were enrolled in study. Sample size was calculated using WHO sample size calculator for two proportions (2-sided) using following values: Test value of population mean $=0.6$, Anticipated population mean $=0.2$, Pooled standard deviation $=0.1$, Power of study $=90 \%$, Level of Significance $=5 \%$, Sample size $=60$ (30 in each group). Non-probability consecutive sampling technique was used. Both male and female patients between 18 and 60 years of age having uncontrolled type 2 diabetes mellitus with $\mathrm{HbA} 1 \mathrm{c}$ taking insulin were included in the study. Chronic liver disease, nephropathy (creatinine $>3.0 \mathrm{mg} / \mathrm{dl}$ ) and Pregnant or lactating mothers were excluded from study. Informed consent was obtained from each participant. Patients were randomly divided into two groups ( $A$ \& $B$ ) using computer generated random number table. Group $A$ was 
given Sitagliptin 50mg per day and dose was increased to $100 \mathrm{mg}$ per day after 2 weeks if fasting blood sugar(FBS) was $\geq 110 \mathrm{mg} / \mathrm{dl}$ or 2 hours postprandial blood sugar (PPBS) $\geq 140 \mathrm{mg} /$ dl. Dose of insulin in group $A$ remained same as before start of study. Group B was kept on same regimen of insulin they were already taking and dose remained same. $\mathrm{HbA} 1 \mathrm{c}$ was done at start of study and after 24 weeks.

Type-II DM was defined as fasting blood sugar (FBS) $\geq 126 \mathrm{mg} / \mathrm{dl}$ or 2 hours' postprandial blood sugar $\geq 200 \mathrm{mg} / \mathrm{dl}$ measured on two different occasions. Patients having $\mathrm{HbA} 1 \mathrm{c}$ more than $7 \%$ were classified as inadequately controlled diabetes mellitus. Primary outcome measure was mean reduction in $\mathrm{HbA} 1 \mathrm{c}$ levels at 24 weeks from baseline.

Information collected comprised age, sex, address, $\mathrm{HbA} 1 \mathrm{c}$ at start of study and $\mathrm{HbA} 1 \mathrm{c}$ at 24 weeks. $\mathrm{HbA} 1 \mathrm{c}$ was done at start of study and after 24 weeks. All the collected information transferred to SPSS version 20 and analyzed accordingly. Mean and standard deviation were calculated for all quantitative variables like age, $\mathrm{HbA} 1 \mathrm{c}$ at baseline and 24 weeks and reduction in $\mathrm{HbA1c}$ at 24 weeks. Frequency and percentage were calculated for all qualitative variables like gender. Paired sample t test, Independent sample t test and chi square test were applied to compare. $\mathrm{P}$ value of $<0.05$ was taken as significant.

\section{RESULTS}

60 patients were included in the study. Mean age was $52.7 \pm 8.43$ years (Table-l). $36(60 \%)$ were male and 24(40\%) were female. (Figure-1).

Mean $\mathrm{HbA} 1 \mathrm{c}$ at base was $8.361 \pm 0.523 \%$ in Group A on Sitagliptin and insulin and $8.187 \pm 0.432 \%$ in group $B$ on insulin alone. Mean $\mathrm{HbA} 1 \mathrm{C}$ at 24 weeks was $7.767 \pm 0.428 \%$ in group $A$ on Sitagliptin and insulin and $7.69+0.407 \%$ in group $B$ on insulin alone (Table-V). Independent sample t-test was applied to change in $\mathrm{HbA} 1 \mathrm{C}$ in Group $A$ and $B$ during 24 weeks of treatment. Mean change in $\mathrm{HbA} 1 \mathrm{C}$ after 24 weeks in Group A was $0.600 \pm 0.315$ and $0.49 \pm 0.19$ in Group B after 24 weeks treatment ( $p$-value 0.002 ) which is highly significant (Table-II).

Paired sample t-test was applied to $\mathrm{HbA} 1 \mathrm{C}$ at baseline and 24 weeks of treatment in group $A$ and group $B$. there was a significant change in both groups after 24 weeks of treatment in both groups ( $p$-value $<0.000$ ) which is highly significant (Table-II).

Chi Square test was applied on efficacy in group A and B. 22(73.33\%) patients in group A and $14(46.67 \%)$ patients in group $B$ achieved significant reduction in $\mathrm{HbA1C}$. $8(26.67 \%)$ patients in group $A$ and $16(53.33 \%)$ patients in group $B$ failed to achieve significant reduction in $\mathrm{HbA1C}$. (P-value < 0.032) which is also highly significant (Table-III).

\begin{tabular}{|l|c|c|c|}
\hline \multicolumn{1}{|c|}{ Age } & All & Group A & Group B \\
\hline $\mathrm{N}$ & 60 & 30 & 30 \\
\hline Mean & 52.73 & 53.27 & 48.32 \\
\hline
\end{tabular}

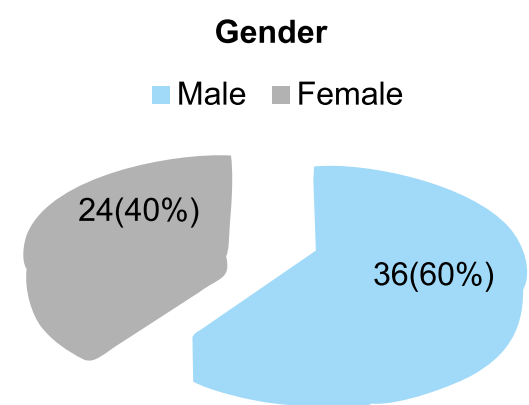

Figure-1. Gender Distribution of Study Population

\begin{tabular}{|l|c|c|c|}
\hline Std. Deviation & 8.43 & 9.028 & 6.345 \\
\hline Minimum & 34 & 37 & 34 \\
\hline Maximum & 69 & 69 & 65 \\
\hline
\end{tabular}

Table-l. Demographics of the study population

\section{DISCUSSION}

Diabetes mellitus is a rapidly increasing epidemic of the modern times. Several drugs are available to treat type 2 diabetes mellitus but eventually diabetic control deteriorates over time. Novel drugs are always needed to improve diabetic control.

DPP-IV inhibitors are newer class of drugs and sitagliptin is most commonly used among this group. The present study has made a comparison 


\begin{tabular}{|c|c|c|c|c|}
\hline \multicolumn{2}{|c|}{ HbA1C } & Group A & Group B & $\begin{array}{c}\text { Independent sample } \\
\text { t-test } \\
\text { P-Value }\end{array}$ \\
\hline \multicolumn{2}{|c|}{ At start of study } & $8.36 \pm .0 .523$ & $8.187 \pm 0.432$ & 0.002 \\
\hline \multicolumn{2}{|c|}{ After 3 months of study } & $7.767 \pm 0.4286$ & $7.690 \pm 0.407$ & 0.002 \\
\hline \multicolumn{2}{|c|}{ Change in $\mathrm{HbA} 1 \mathrm{C}$ after 24 weeks of treatment } & $0.6000+0.3151$ & $0.496+0.190$ & 0.002 \\
\hline \multicolumn{2}{|c|}{ Paired sample t-test ( $p$ value) } & 0.000 & 0.000 & \\
\hline \multicolumn{5}{|c|}{ Table-II. Independent sample t-test and paired sample t-test } \\
\hline & & \multicolumn{2}{|c|}{ Efficacy } & Total \\
\hline & & Yes & No & Iotal \\
\hline \multirow{2}{*}{ Group } & A & $22(73.33 \%)$ & $8(26.67 \%)$ & 30 \\
\hline & B & $14(46.67 \%)$ & $16(53.33 \%$ & 30 \\
\hline \multicolumn{2}{|c|}{ Total } & & & 60 \\
\hline \multicolumn{2}{|c|}{ Chi Square Value } & \multicolumn{3}{|c|}{4.444} \\
\hline \multicolumn{2}{|c|}{$p$-value } & \multicolumn{3}{|c|}{0.032} \\
\hline
\end{tabular}

of sitagliptin-insulin combination with insulin alone in the treatment of type-IIDM for glycemic control in patients uncontrolled on insulin alone. The study has shown that sitagliptin as add on therapy to patients already taking insulin and still uncontrolled significantly improved glycemic control by reducing $\mathrm{HbA} 1 \mathrm{C}$ after 6 months as compared to patients taking insulin alone ( $p$ value $=0.002$ ). There was a significant reduction of $\mathrm{HbA1C}$ in type-II DM P-Value $=0.0001$ ).

In 2013, Shimoda S et al conducted a study in Japanese population to evaluate the effects of addition of sitagliptin, an oral DPP-IV inhibitor, in people with type-II DM inadequately controlled on complex insulin regimens. HbA1c was significantly reduced during the first 12 weeks $(-0.64 \pm 0.60 \%)$, and was maintained over 24 weeks $(-0.69 \pm 0.85 \%)$. This is comparable to the results of our study in which adding sitagliptin also improved glycemic control significantly by decreasing $\mathrm{HbA} 1 \mathrm{C} .^{9}$

Giampetro $\mathrm{O}$ et al found out that in type-II $\mathrm{DM}$, the combination of insulin and sitagliptin improved lipid profile and metabolic control and significantly decreased insulin requirements. It is the same as in our study which also showed similar results. ${ }^{22}$

In one study by Katsuno $\mathrm{T}$ etal, addition of sitagliptin to people with type-II DM on insulin improved $\mathrm{HbA} 1 \mathrm{C}$ significantly from $8.1 \pm 1.2 \%$ to
$7.6 \pm 1.1 \%$ over a 12 weeks of therapy with addition of sitagliptin $(p<0.01)$, and the insulin dosage was reduced from $27.3 \pm 15.8$ Units/day to $24.5 \pm 16.5$ Units /day $(p<0.001)$. The results of this investigation confirmed that addition of sitagliptin to insulin can improve glycemic control without increasing risk of hypoglycemia and/or weight gain. It also confirms the results of our study which shows that sitagliptin improves glycemic control when added to patients on insulin. ${ }^{23}$

Astudy done by HariKumar KV etal showed that the exenatide and/or sitagliptin addition significantly decreases insulin dosage without increase in endogenous insulin production or hypoglycemic episodes. This result is also supportive of the results of my study that sitagliptin improves diabetic control in patients on insulin alone. ${ }^{24}$

Mori $Y$ et al conducted a similar study in 2013 in Japanese population and he found that the addition of sitagliptin significantly decreases in 24 hour mean glucose levels measured by continuous glucose monitoring(CGM) $(\mathrm{P}<0.01){ }^{25}$

It was a small study with a sample size of 60 with non-randomized sampling and no double blinding. Large randomized controlled trials are needed to further validate these results.

CONCLUSIONS AND RECOMMENDATIONS 
It has been concluded from this study that insulin and sitagliptin-insulin combination both significantly reduce $\mathrm{HbA1C}$ in type 2 diabetes mellitus.

However addition of sitagliptin to patients already taking insulin and uncontrolled, is more effective than insulin for glycemic control of patients with type 2 diabetes mellitus.

Copyright(C) 23 Sep, 2017

\section{REFERENCE}

1. World Health Organization. Diabetes. Fact sheet no. 312. 2009. Available at http://www.who.int/mediacentre/ factsheets/fs312/en/ Last accessed 14 January 2011.

2. Shichiri M, Kishikawa H, Ohkubo $Y$, Wake N. Longterm results of the Kumamoto Study on optimal diabetes control in type 2 diabetic patients. Diabetes Care. 2000; 23; 2:21-9.

3. UK Prospective Diabetes Study (UKPDS) Group. Intensive blood-glucose control with sulphonylureas or insulin compared with conventional treatment and risk of complications in patients with type 2 diabetes (UKPDS 33) Lancet. 1998; 352:837-53.

4. Hakeem R, Fawwad A. Diabetes in Pakistan: Epidemiology, Determinants and Prevention. Journal of Diabetology, October 2010; 3:4.

5. Forbes JM, Cooper ME. Mechanisms of diabetic complications. Physiol Rev. 2013; 93:137-88.

6. Kutoh E. Sitagliptin is effective and safe as add-on to insulin in patients with absolute insulin deficiency: a case series. Journal of Medical Case Reports 2011, $5: 117$.

7. Zinman B. Initial combination therapy for type 2 diabetes mellitus: is it ready for prime time? $\mathrm{Am} \mathrm{J}$ Med. 2011; 124:S19-34.

8. Martin C. Michel, Eric Fliers, Cornelis J. F. Van Noorden. Dipeptidyl peptidase IV inhibitors in diabetes: more than inhibition of glucagon-like peptide1metabolism? Naunyn Schmiedebergs Arch Pharmacol. 2008; 377: 205-7.

9. Shimoda S, Iwashita S, Ichimori S, Matsuo Y, Goto $R$, Maeda $T$ et al. Efficacy and safety of sitagliptin as add-on therapy on glycemic control and blood glucose fluctuation in Japanese type 2 diabetes subjects ongoing with multiple daily insulin injections therapy. Endocr J. 2013; 60:1207-14.

10. Nonaka K, Kakikawa T, Sato A et al. Efficacy and safety of sitagliptin monotherapy in Japanese patients with type 2 diabetes. Diabetes Res ClinPract 2008; 79: $291-$ 8.

11. Mashrani U. Diabetes mellitus \& hypoglycemia. In: McPhee, SJ, Papdakis MA, editors. Current medical diagnosis and treatment. 45th ed. New York: Mc GrawHill; 2012 p. 1192.

12. Kutoh E. Sitagliptin is effective and safe as add-on to insulin in patients with absolute insulin deficiency: a case series. Journal of Medical Case Reports 2011, $5: 117$.

13. Green J, Feinglos M. New combination treatments in the management of diabetes: focus on sitagliptin metformin. Vasc Health Risk Manag. 2008; 4: 743-51.

14. Vilsbøll T, Rosenstock J, Yki-Järvinen $\mathrm{H}$, Cefalu WT, Chen Y, Luo E et al. Efficacy and safety of sitagliptin when added to insulin therapy in patients with type 2 diabetes. Diabetes ObesMetab. 2010; 12:167-77.

15. Arase $Y$, Suzuki F, Kobayashi M, Suzuki Y, Kawamura Y, Matsumoto $\mathrm{N}$ et al. Efficacy and safety in sitagliptin therapy for diabetes complicated by chronic liver disease caused by hepatitis $\mathbf{C}$ virus. Hepatol Res. $2011 ; 41: 524-9$.

16. St. Onge EL, Miller S, Clements E. Sitagliptin/ Metformin (Janumet) as Combination Therapy In the Treatment of Type-2 Diabetes Mellitus. Pharmacy and Therapeutics. 2012; 37(12):699-708.

17. Arase $Y$, Suzuki F, Kobayashi M, Suzuki Y, Kawamura $Y$, Matsumoto N, et al. Efficacy and safety in sitagliptin therapy for diabetes complicated by chronic liver disease caused by hepatitis $\mathbf{C}$ virus. Hepatol Res. 2011; 41:524-9.

18. Arjona Ferreira JC, Corry D, Mogensen CE, Sloan L, Xu L, Golm GT, Gonzalez EJ, Davies MJ, Kaufman KD, Goldstein BJ. Efficacy and Safety of Sitagliptin in Patients With Type 2 Diabetes and ESRD Receiving Dialysis: A 54-Week Randomized Trial. Am J Kidney Dis. 2013; 23; 272-86.

19. Boerner BP, Miles CD, Shivaswamy V. Efficacy and safety of sitagliptin for the treatment of newonset diabetes after renal transplantation. Int $\mathrm{J}$ Endocrinol. 2014; 2014:617638.

20. Harashima SI, Tanaka D, Yamane S, Ogura M, Fujita $Y$, Murata $Y$ etal. Efficacy and safety of switching from basal insulin to sitagliptin in Japanese type 2 diabetes patients. HormMetab Res. 2013; 45:231-8.

21. Hong ES, Khang AR, Yoon JW, Kang SM, Choi SH, Park KS etal. Comparison between sitagliptin as add-on therapy to insulin and insulin dose-increase therapy in uncontrolled Korean type 2 diabetes: CSI study. 
Diabetes ObesMetab. 2012; 14:795-802.

22. Giampietro O, Giampietro C, Bartola LD, Masoni MC, Matteucci E. Sitagliptin as add-on therapy in insulin deficiency: biomarkers of therapeutic efficacy respond differently in type 1 and type 2 diabetes. Drug Des DevelTher. 2013; 7:99-104.

23. Katsuno T, Ikeda H, Ida K, Miyagawa J, Namba M. Add-on therapy with the DPP-4 inhibitor sitagliptin improves glycemic control in insulin-treated Japanese patients with type 2 diabetes mellitus. Endocr J. 2013; 60:73342.

24. Hari Kumar KV, Shaikh A, PrustyP. Addition of exenatide or sitagliptin to insulin in new onset type 1 diabetes: a randomized, open label study. Diabetes Res ClinPract. 2013; 100:55-8.

25. Mori Y, Taniguchi Y, Miyazaki S, Yokoyama $\mathrm{J}$, Utsunomiya K. Effects of add-on treatment with sitagliptin on narrowing the range of glucose fluctuations in Japanese type 2 diabetes patients receiving insulin therapy. Diabetes TechnolTher. 2013; 15:237-40.

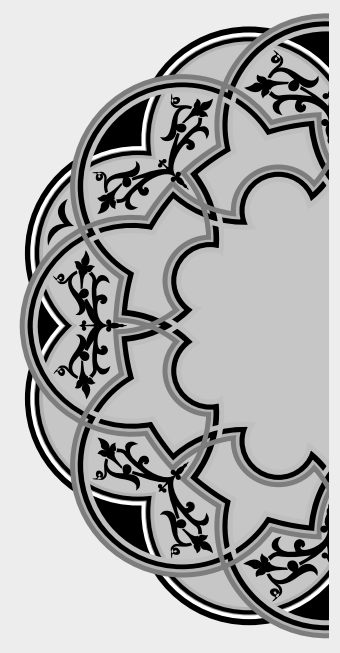

\title{
"Don't think outside the box. Think like there is no box."
}

\author{
Unknown
}

\section{AUTHORSHIP AND CONTRIBUTION DECLARATION}

\begin{tabular}{|c|l|l|l|}
\hline Sr. \# & \multicolumn{1}{|c|}{ Author-s Full Name } & \multicolumn{1}{|c|}{ Contribution to the paper } & Author=s Signature \\
\hline 1 & Zaheer Ahmed & Manuscript Writing \\
\hline 2 & Hassan Fareed & Data collection \\
\hline 3 & M. Usman Musharraf & Data collection \\
\hline
\end{tabular}

